\title{
Implementasi sistem manajemen keselamatan dan kesehatan kerja di Pt. Pln (Persero) Rayon Rote Ndao
}

\author{
Tudermi Maksimilyan Fioh'; Anderias Umbu Roga²; Johny A. R Salmun ${ }^{3}$; \\ *Franky M. S. Telupere ${ }^{4}$ \\ ${ }^{1-3}$ Prodi Kesehatan Lingkungan dan Kesehatan Kerja, Fakultas Kesehatan Masyarakat \\ Universitas Nusa Cendana \\ ${ }^{4}$ Fakultas Peternakan, Universitas Nusa Cendana \\ *E-mail korespondensi: papyt2018@gmail.com
}

\begin{abstract}
The determining or the implementation of occupational safety and health management system is an obligation for all companies as is already mandated in Government Regulation Number 50 in 2012. The implementation have an aim to reduce the risk level of work accident noraltough the occupational illness which may be happening in work environment. The aim of this research is to cover the implementation of occupational safety and health management system at PT. PLN (Persero) Rayon Rote Ndao. This research is using descriptive analysis method with total five informants which are consist of the manager of PT.PLN (Persero) Rayon Rote Ndao, supervisor $K 3$, office employee, field employee and engineer. The research result shows that theoccupational safety and health management system's commitment and the policy, the occupational safety and health management system's planning, the occupational safety and health management system's implementation, the occupational safety and health management system's measurement and evaluation, and the occupational safety and health management system's review and improvement in PT.PLN (Persero) Rayon Rote Ndao have already been well applyed.
\end{abstract}

Keywords: Implementation, Managemen K3, PT. PLN

\section{PENDAHULUAN}

Tenaga kerja mempunyai peranan dan kedudukan yang sangat penting sebagai pelaku dan tujuan pembangunan dalam pelaksanaan pembangunan nasional.Sesuai dengan peranan dan kedudukan tenaga kerja, diperlukan pemberdayaan ketenagakerjaan untuk meningkatkan kualitas tenaga kerja dan peransertanya dalam pembangunan serta peningkatan perlindungan tenaga kerja dan keluarganya sesuai dengan harkat dan martabat kemanusiaan. Perlindungan terhadap tenaga kerja dimaksudkan untuk menjamin hak-hak dasar pekerja atau buruh dan menjamin kesamaan kesempatan serta perlakuan tanpa diskriminasi (Salafudin, 2013).

Industrialisasi, mekanisasi, elektrifikasi dan modernisasi yang semakin maju setiap tahunya berdampak pada banyak hal, seperti peningkatan intensitas kerja personil dan tempo kerja para pekerja atau buruh. Kelelahan, kurang perhatian akan hal-hal lain, kehilangan keseimbangan dan lain-lain merupakan sebab terjadinya kecelakaan (UU 
No. 1 Tahun 1970). Kecelakaan kerja sebenarnya dapat dicegah, karena kecelakaan itu tidak terjadi dengan sendirinya. Suatu kecelakaan kerja hanya akan terjadi apabila terdapat berbagai faktor penyebab secara bersamaan pada suatu tempat kerja atau proses produksi. Beberapa penelitian memberikan indikasi bahwa suatu kecelakaan kerja tidak dapat terjadi dengan sendirinya, akan tetapi terjadi oleh satu atau beberapa faktor penyebab kecelakaan sekaligus dalam suatu kejadian (Tarwaka,2012:22). Perlindungan terhadap tenaga kerja dimaksudkan untuk menjamin hak-hak dasar pekerja atau buruh dan menjamin kesamaan kesempatan serta perlakuan tanpa diskriminasi atas dasar apapun untuk mewujudkan kesejahteraan pekerja atau buruh dan keluarganya dengan tetap memperhatikan perkembangan kemajuan dunia usaha (UU No. 13 Tahun 2003).

Penerapan atau implementasi Sistem Manajemen Keselamatan dan Kesehatan Kerja (SMK3) merupakan kewajiban setiap perusahaan sebagaimana yang diamanatkan dalam Peraturan Pemerintah Nomor 50 Tahun 2012. Penerapan tersebut bertujuan untuk mengurangi tingkat risiko kecelakaan kerja maupun penyakit akibat kerja yang mungkin terjadi di tempat kerja.

PT. Perusahaan Listrik Negara (PLN) adalah Badan Usaha Milik Negara yang berbentuk Perusahaan Perseroan (Persero) berkewajiban untuk menyediakan tenaga listrik bagi kepentingan umum. Potensi bahaya yang ada dalam perusahaan ini cukup besar antara lain tersengat arus listrik, terjatuh dari ketinggian tiang, tertimpa alat-alat berat yang digunakan pada saat proses kerja dilapangan, kebisingan, serta risiko-risiko bahaya lainnya yang sangat rawan bagi para pekerja teknik tersebut.

Secara global, International Labour Organization (ILO) memperkirakan sekitar 337 juta kecelakaan kerja terjadi setiap tahunnya yang mengakibatkan 2,3 juta pekerja kehilangan nyawa,sementara itu data kecelakaan kerja pada tahun 2018 yang dikeluarkan oleh Badan Penyelenggara Jaminan Sosial (BPJS) Ketenagakerjaan sebanyak 173.105 kasus. Data ini menunjukkan adanya peningkatan jumlah kasus kecelakaan kerja dari tahun sebelumnya yakni 2017 sebesar 123.041 kasus. Berdasarkan data nasional selama kurun waktu tahun 2017 hingga triwulan I (satu) tahun 2018, terjadi kecelakaan kerja pada tenaga kerja PT.PLN (Persero) sebanyak 20 (dua puluh) kasus kecelakaan kerja yang mengakibatkan korban meninggal dunia sebanyak 14 tenaga kerja dan korban mengalami luka bakar serius sebanyak 6 tenaga kerja. Berdasarkan data 3 (tiga) tahun terakhir yakni 2016-2018 yang dikeluarkan oleh Badan Penyelenggara Jaminan Sosial (BPJS) Ketenagakerjaan Provinsi Nusa Tenggara Timur, tercatat sebanyak 166 kasus kecelakaan kerja dengan rincian tahun 2016 sebanyak 19 kasus, tahun 2017 sebanyak 76 kasus, dan tahun 2018 sebanyak 71 kasus, di mana terdapat 3 kasus kecelakaan kerja pada karyawan PLN yakni tahun 2017 sebanyak 1 kasus kecelakaan kerja, dan tahun 2018 sebanyak 2 kasus kecelakaan kerja.

Penelitian yang dilakukan oleh Salafudin (2013) terkait implementasi SMK3 di PT. PLN Jawa Tengah dan Yogyakartadiperoleh informasi bahwa SMK3sudah berjalan dengan baik dan sesuai dengan peraturan yang berlaku. Meski demikian pelaksanaannya masih perlu diperbaiki, terutama pada tahapan inspeksi dan evaluasi.Hal yang paling penting adalah bahwa penerapan K3 ini memberikan dampak atau implikasi terhadap mutu dan produktivitas kerja karyawan, meskipun penilaian SMK3 yang ada hanya mencapai nilai 55\%. PT. PLN (Persero) Rayon Rote Ndao merupakan salah satu perusahaan milik negara yang bergerak dalam bidang penyalur listrik. Kegiatan perusahaan ini adalah menyalurkan energi listrik bagi setiap pelanggan khususnya di daerah Rote Ndao.

Pada 3 (tiga) tahun terakhir (2015-2017), berdasarkan wawancara awal diperoleh informasi bahwa terjadi 4 (empat) kasus kecelakaan kerja di PT. PLN (Persero) Rayon 
Rote Ndao. Kecelakaan kerja yang dialami oleh pekerja tersebut antara lain: mengalami luka potong saat pemotongan pipa untuk keperluan instalasi listrik, terjatuh saat pembersihan jaringan kabel listrik. Selain itu salah satu tenaga kerja bagian mesin mengalami penyakit akibat kerja berupa gangguan pendengaran akibat terpapar kebisingan dalam jangka waktu yang lama. Informasi tambahan diketahui bahwa tenaga kerja menggunakan Alat Pelindung Diri (APD) hanya pada pekerjaan yang dianggap berat dan berisiko tinggi, sedangkan yang dianggap ringan dan tidak berisiko tinggi mereka tidak menggunakan APD.

PT.PLN (Persero) sebagai satu-satunya perusahaan yang bergerak di bidang penyaluran energi listrik, beban kerja bagi tenaga kerja atau karyawannya cukup tinggi di tengah tuntutan masyarakat terhadap pelayanan listrik yang prima dan optimal. Beban kerja yang besar dan lingkungan kerja dengan tingkat risiko yang tinggi pada perusahaan ini memungkinkan terjadinya kecelakaan kerja maupun penyakit akibat kerja bagi para tenaga kerja.

Merujuk pada data kecelakaan kerja maupun fakta tingginya risiko kerja di PT.PLN (Persero) Rayon Rote Ndao, maka diperlukan upaya pengendalian risiko melalui penerapan Sistem Manajemen Keselamatan dan Kesehatan Kerja (SMK3) secara baik dan benar sesuai dengan regulasi yang berlaku. Penerapan SMK3 bertujuan untuk memberikan perlindungan yang optimal bagi tenaga kerja agar dapat bekerja dalam lingkungan kerja yang aman dan dapat mendukung peningkatan kinerja dan produktivitas kerja.

\section{METODE PENELITIAN}

Jenis penelitian ini merupakan penelitian kualitatif dengan menggunakan metode deskriptifanalisis, yaitu peneliti mau menggambarkan implementasi Sistem Manajemen Keselamatan dan Kesehatan Kerja dengan harapan permasalahan yang akan diulas disini menjadi lebih terlihat lebih jelas dan sudah sesuai dengan ketentuan peraturan yang berlaku. Metode Penelitian adalah cara yang digunakan oleh peneliti dalam mengumpulkan data penelitiannya. Dengan demikian penyusunan metode penelitian dimaksudkan agar peneliti dapat menghasilkan suatu kesimpulan yang dapat dipertanggungjawabkan secara ilmiah. Penelitian ini peneliti mengambil narasumber sebanyak limainforman yang meliputi Manajer PT. PLN (Persero) Rayon Rote Ndao, Supervisor K3, karyawan kantor, karyawan lapangan, dan karyawan bagian mesin.

\section{HASIL DAN BAHASAN Hasil}

Berdasarkan variabel penelitian yang diteliti yakni Sistem Manajemen K3 yang meliputi: Komitmen dan Kebijakan, Perencanaan, Penerapan, Pengukuran dan Evaluasi, serta Tinjauan Ulang melalui wawancara terhadap 5 (lima) narasumber atau informan yakni Manajer PT.PLN (Persero) Rayon Rote Ndao, Supervisor K3, Karyawan kantor, Karyawan bagian jaringan dan Karyawan bagian mesin diperoleh hasil sebagai berikut:

\section{Komitmen dan Kebijakan Sistem Manajemen Keselamatan dan Kesehatan Kerja}

PT. PLN (Persero) Rayon Rote Ndao mempunyai komitmen dan kebijakan untuk mengimplementasikan Sistem Manajemen Keselamatan dan Kesehatan Kerja secara lebih optimal. Berdasarkan hasil wawancara terhadap informan 1 dan 2, diperoleh jawaban sebagai berikut: 
"Ya, ada implementasi dilaksanakannya K3.. itu salah satu kebijakan internal perusahaan kami, sebagai contohnya adalah adanya APD yang disiapkan perusahaan, adanya koordinator $K 3$ kemudian adanya rambu-rambu/tanda-tanda $K 3$ yang disiapkan” (Informan 1, MTG).

"Ya pak, ada komitmen internal perusahaan berupa kontrak SLA. Selain itu kami juga punya tujuh komitmen keselamatan kerja untuk mewujudkan zero accident, begitu pak" (Informan 2, RWW).

Berdasarkan informasi tambahan dari informan 3 dan informan 5 terkait variabel komitmen dan kebijakan ini diperoleh jawaban bahwa pihak PT. PLN (Persero) Rayon Rote Ndao memberi perhatian yang cukup besar bagi pelaksanaan K3 di dalam perusahaan, seperti yang terlihat dalam jawaban informan sebagai berikut:

"Pihak perusahaan su siapkan semua SOP kaka, jadi kalo soal komitmen K3 PLN beta rasa su cukup bae kaka. Selain itu, perusahaan ju su siapkan APD buat ketong karyawan dong jadi tinggal pake sa" (Informan 3, JO).

"Kalo soal komitmen dan kebijakan perusahaan na menurut beta katong di PLN punya komitmen yang kuat soal K3. Contohnya,di sini semua karyawan khususnya katong yang di bagian mesin deng jaringan dong diwajibkan pake APD saat kerja. Trus itu APD dong perusahaan yang siapkan kaka” (Informan 5, MJK).

Sesuai dengan jawaban diatas diketahui bahwa pihak perusahaan PT. PLN (Persero) Rayon Rote Ndao telah memiliki komitmen dan kebijakan yang serius dalam upaya mengimplementasikan SMK3 secara baik.

\section{Perencanaan Sistem Manajemen Keselamatan dan Kesehatan Kerja}

Pada variabel perencanaan K3 sesuai dengan Rencana Kerja Anggaran Perusahaan (RKAP) tahun 2019 terdapat beberapa rencana pembangunan seperti yang dijelaskan oleh informan 1 dan 2 sebagai berikut:

"Perencanaan yang kami buat adalah pembangunan hydrant pemadam kebakaran, Pengadaan APD secara berkala dan lain-lain. Saya tidak hafal semua tapi itu perencanaan sudah dimuat dalam RKAP pak. Pak bisa lihat di supervisor K3" (Informan 1, MTG).

"Adanya RKAP yang juga memuat tentang kebutuhan K3 kemudian RKAP diidentifikasi dan ditindaklanjuti dalam realisasi anggaran pak. Jadi kami buat perencanaan sesuai kebutuhan saat ini pak" (Informan 2, RWW).

Sesuai dengan jawaban diatas perusahaan PT. PLN (Persero) Rayon Rote Ndao telah memiliki perencanaan SMK3 sebagai bentuk komitmen perusahaan dalam mengimplementasikan SMK3.

\section{Penerapan Sistem Manajemen Keselamatan dan Kesehatan Kerja}

Pada variabel penerapan K3 yang dikoordinir langsung oleh supervisor K3 sudah dilaksanakan dengan mengacu pada Standart Operational Procedure (SOP) yang telah ditetapkan oleh perusahaan Berdasarkan wawancara terhadap I 1, I 2, I 3, I 4 dan I 5 diperoleh hasil sebagai berikut:

"Ya, sudah ada penerapan K3 dengan baik, apalagi kami juga sudah punya supervisor K3 yang mengkoordinir langsung masalah K3 pak" (Informan 1, MTG).

"Kami sudah berusaha menerapkan dengan baik, misalnya adanya kegiatan pendukung K3 seperti adanya simulasi kebakaran, gelar pasukan dan lain-lain" (Informan 2,RWW). 
"Katong kerja di sini wajib perhatikan K3 kaka. Katong ju harus pake APD tiap kali kerja di lapangan kaka. Intinya katong di sini kerja iko SOP sa kaka. Jadi kalo soal penerapan na jelas kaka. Kalo soal APD na itu perusahaan yang siap kasih ketong jadi katong bawa ko pake" (Informan 3, JO).

"Begini kaka, katong kerja di PLN nih semua yang katong kerja harus iko SOP kaka. Sonde bisa kerja di luar SOP kaka karena itu aturan perusahaan. Kalo K3 tuh su pasti kaka. Ko katong ju tau itu menyangkut keselamatan kerja na kaka" (Informan 4, FRN).

"Katong yang di bagian mesin nih kerja resiko tinggi o, makanya katong kerja iko SOP sa. Pokoknya perusahaan su kasih SOP karmana na iko sa su. Perusahaan ju siap kasih katong APD ko katong pake. Itu penting kaka, pake ko jang celaka waktu karja to" (Informan 5, MJK).

Sesuai dengan jawaban diatas penerapan SMK3 di PT. PLN (Persero) Rayon Rote Ndao telah dilaksanakan dengan baik.

\section{Pengukuran dan Evaluasi Sistem Manajemen Keselamatan dan Kesehatan Kerja}

Pada variabel pengukuran,pemantauan dan evaluasi kinerja K3 juga sudah dilaksanakan dengan baik. Berdasarkan hasil wawancara terhadap informan I 1 dan I 2 diperoleh hasil sebagai berikut:

"Adanya inspeksi yang dilakukan oleh Unit Pelaksana Pelayanan Pelanggan (UP3) terhadap kinerja manajemen rayon Rote Ndao. Selain itu ada pula audit internal K3 yang dilaksanakan oleh UP3 dan Supervisor K3” (Informan 1, MTG).

"Ya, Selalu ada pemantauan dan evaluasi yang dilakukan oleh saya terhadap kegiatan di lapangan dan para karyawan selalu melaporkan pekerjaan mereka melalui dokumentasi dan juga saya turun lapangan untuk mengawasi langsung” (Informan 2, RWW).

Berdasarkan informasi tambahan dari informan 3 terkait variabel pengukuran dan evaluasi SMK3 ini diperoleh jawaban bahwa pihak PT. PLN (Persero) Rayon Rote Ndao melalui supervisor K3 selalu melakukan pengawasan dan evaluasi terhadap kinerja para karyawan terkait kepatuhan terhadap prinsip-prinsip K3 khususnya penggunaan APD dan juga termasuk pelaksanaan pekerjaan yang harus sesuai dengan SOP yang telah ditetapkan, sebagaimana jawaban informan 3 dan informan 5 berikut ini:

"Kalo katong ada karja di lapangan, biasanya supervisor $K 3$ ju turun awasi langsung katong kaka. Jadi katong ju kerja terkontrol kaka” (Informan 3, JO).

Sesuai dengan jawaban diatas diketahui bahwa pihak perusahaan PT. PLN (Persero) Rayon Rote Ndao telah melakukan pengukuran dan evaluasi SMK3 dengan baik.

\section{Tinjauan Ulang dan Peningkatan Sistem Manajemen Keselamatan dan Kesehatan Kerja}

Pada variabel tinjauan ulang dan peningkatan SMK3, juga telah dilaksanakan dengan baik sebagaimana penjelasan informan I 1 dan I 2 pada saat wawancara, yakni:

"Adanya sosialisasi secara berkelanjutan tentang pentingnya K3 baik itu kepada karyawan, satuan pengamanan dan edukasi kepada mitra kerja pelayanan teknik. Selain itu ada juga evaluasi terhadap para karyawan terkait kepatuhan dalam penggunaan APD dan mematuhi prinsip-prinsip K3. Salah satu bentuk evaluasi kepatuhan penggunaan APD terhadap para karyawan dilakukan melalui adanya kewajiban mendokumentasikan dan melaporkan setiap pekerjaan yang dilakukan oleh para karyawan kepada pihak manajemen perusahaan melalui Supervisor K3 (Informan 1, MTG). 
"Adanya inspeksi mendadak dan punishment, misalnya adanya surat peringatan 1 dan 2 dan surat pemutusan kontrak jika sudah lebih dari 2 kali teguran terhadap pekerja yang lalai dalam menggunakan APD saat bekerja”. Selain itu kami juga laksanakan sosialisasi secara rutin per triwulan bagi semua karyawan seperti karyawan jaringan/teknik, satuan pengamanan dan lainnya” (Informan 2, RWW).

Sesuai dengan jawaban diatas pihak perusahaan PT. PLN (Persero) Rayon Rote Ndao telah melakukan tinjauan ulang SMK3 sesuai dengan baik.

\section{Bahasan}

\section{Komitmen dan Kebijakan}

Berdasarkan Peraturan Pemerintah Nomor 50 Tahun 2012 tentang Sistem Manajemen Keselamatan dan Kesehatan Kerja (SMK3) dan berbagai regulasi lainnya maka setiap perusahaan wajib menerapkan SMK3 di perusahaannya. Perusahaan Listrik Negara (PLN) sebagai salah satu Badan Usaha Milik Negara yang menyediakan layanan kelistrikan pun juga wajib menerapkan SMK3 dalam berbagai pekerjaan yang dilakukan.

Hasil penelitian yang dilakukan di PT.PLN (Persero) Rayon Rote Ndao khususnya pada variabel Komitmen dan Kebijakan diketahui bahwa pihak PT.PLN (Persero) Rayon Rote Ndao telah memiliki komitmen yang kuat dalam implementasi SMK3. Hal ini terlihat dari komitmen manajemen perusahaan di dalam mencapai zero accident melalui 7 (tujuh) Komitmen Keselamatan Kerja yakni: Siap Sumber Daya Manusia (SDM) yang kompeten, Siap Standard Operating Procedure (SOP), Siap Alat Pelindung Diri (APD), Siap tool, Siap JobSafetyAnalysis (JSA),Siap rambu-rambu, dan Mesin/instalasi aman.Hal ini juga terlihat melalui komitmen manajamen perusahaan di dalam perencanaan terkait K3 yang termuat di dalam Rencana Kerja Anggaran Perusahaan (RKAP) tahun 2019.

Berdasarkan Rencana Kerja Anggaran Perusahaan (RKAP) tahun 2019 pada bagian Kepemimpinan, Kebijakan dan Komitmen Manajemen terdapat beberapa rencana kegiatan antara lain: Edukasi dan upaya pencegahan kecelakaan masyarakat umum di setiap unit induk dan unit pelaksana; menyediakan sistem proteksi kebakaran untuk kantor induk, kantor unit pelaksana, kantor sub unit pelaksana dan instalasi ketenagalistrikan sesuai dengan identifikasi bahaya, penilaian risiko dan pengendalian risiko; melaksanakan simulasi penggunaan peralatan proteksi kebakaran dan simulasi tanggap darurat di unit induk dan unit pelaksana; melakukan pengukuran lingkungan kerja (temperatur, kebisingan, pencahayaan) dan melakukan pemeriksaan kesehatan bagi $100 \%$ pegawai yang berhak; melakukan pengukuran hygiene faktor mitra kerja di unit; melaksanakan rapatPanitia Pembina Keselamatan dan Kesehatan Kerja(P2K3) tiap bulan di unit induk dan seluruh unit pelaksana serta membuat laporan P2K3 ke Dinas Tenaga Kerja setempat (RKAP Tahun 2019).

Selain berdasarkan Rencana Kerja Anggaran Perusahaan (RKAP) tahun 2019 di atas ada juga komitmen dan kebijakan perusahaan tentang wajib implementasi K3 yang dilengkapi dengan sarana dan prasarana pendukung K3 seperti Alat Pelindung Diri (APD) bagi setiap karyawan, adanya koordinator atau supervisor bidang K3, adanya rambu-rambu (tanda bahaya, perintah,dll) terkait K3 yang dipasang di area-area strategis perusahaan.

Salafudin M (2013) dalam penelitian terdahulu di PT. PLN (Persero) Area Pengatur Distribusi Jawa Tengah dan D.I.Yogyakarta menyatakan bahwa "Terdapat kebijakan lain yang juga menjadi komitmen PT PLN (Persero) Area Pengatur Distribusi Jawa Tengah dan D.I.Yogyakarta dalam upaya mengoptimalkan penerapan SMK3 seperti mewujudkan Zero Accident dalam setiap pekerjaan, baik di lapangan maupun 
dilingkungan kantor PT PLN (Persero) Area Pengatur Distribusi Jawa Tengah \& D.I.Yogyakarta. Selain itu terdapat juga penyempurnaan Standard Operation Procedure (SOP) yang rutin dilakukan demiterciptanya Zero Accident".

Berdasarkan penelitian terdahulu tersebut, diketahui bahwa pihak PT. PLN (Persero) sebagai Badan Usaha Milik Negara (BUMN) bersama seluruh jajarannya memiliki komitmen yang kuat dalam mewujudkan keselamatan dan kesehatan kerja melalui implementasi SMK3 di dalam perusahaan tersebut.

\section{Perencanaan}

Unsur penting dalam manajemen di antaranya adalah perencanaan. Oleh karena itu, di dalam SMK3 perencanaan merupakan salah satu unsur yang harus dilaksanakan oleh pihak perusahaan. Berdasarkan hasil penelitian khususnya pada variabel penelitian, diketahui bahwa pihak PT.PLN (Persero) Rayon Rote Ndao telah menyiapkan perencanaan terkait K3 dengan baik. Hal itu terlihat dari adanya perencanaan sebagaimana yang terangkum di dalam Rencana Kerja Anggaran Perusahaan (RKAP) tahun 2019 yang memuat berbagai rencana program dan kegiatan terkait K3, misalnya: pemasangan paving block, pemasangan Closed Circuit Television (CCTV), pembangunan pos Satuan Pengamanan (Satpam), hydrant pemadam kebakaran, pemasangan rambu-rambu K3, pemasangan kanopi parkir, dan pembangunan gudang. Adanya perencanaan yang baik ini menjadi salah satu indikator bahwa pihak perusahaan memiliki komitmen dan kebijakan serta keseriusan dalam mengimplementasikan SMK3 melalui perencanaan yang matang dan komprehensif.

Salafudin M (2013) dalam penelitian terdahulu di PT. PLN (Persero) Area Pengatur Distribusi Jawa Tengah dan D.I.Yogyakarta menyatakan bahwa "Perencanaan dalam hal ini juga meliputi perencanaan yang berkaitan dengan identifikasi bahaya, penilaian risiko dan pengendalian risiko. PT PLN (Persero) AreaPengatur Distribusi Jawa TengahD.I.Yogyakarta membentuk tim identifikasi bahaya, penilaiaan dan pengendalian risiko dengan menunjuk masing-masing satu orang karyawan disetiap divisi yang ada. Dengan perincian tugas untuk melakukan identifikasi bahaya maupun risiko kecelakaan pekerjaan yang mungkin terjadi di masing-masing divisi yang ada".

Berdasarkan penelitian terdahulu tersebut, diketahui bahwa pihak PT. PLN (Persero) sebagai BUMN bersama seluruh jajarannya memiliki komitmen yang kuat dalam mewujudkan keselamatan dan kesehatan kerja melalui perencaanaan SMK3 yang baik di dalam perusahaan tersebut.

\section{Penerapan}

Unsur utama dalam SMK3 adalah unsur penerapan. Tanpa penerapan yang konsisten dan berkelanjutan sesuai dengan regulasi yang berlaku maka dipastikan SMK3 tak dapat diimplementasikan dengan baik. Oleh karena itu, setiap perusahaan wajib menerapkan SMK3 dengan baik sesuai dengan regulasi atau peraturan yang diwajibkan bagi setiap perusahaan.

Berdasarkan hasil penelitian khususnya pada variabel penerapan, diketahui bahwa pihak manajemen PT.PLN (Persero) Rayon Rote Ndao telah berupaya optimal dalam penerapan SMK3. Hal ini terlihat melalui berbagai upaya dan kegiatan yang dilakukan oleh pihak perusahaan seperti: adanya kewajiban bagi semua karyawan untuk bekerja sesuai dengan SOP, adanya kewajiban bagi para karyawan untuk selalu memperhatikan dan melaksanakan prinsip-prinsip K3 dalam bekerja misalnya wajib menggunakan APD bagi para pekerja lapangan/jaringan saat melaksanakan pekerjaan di lapangan, dan juga 
adanya kegiatan pendukung dalam penerapan $\mathrm{K} 3$ seperti adanya simulasi penanggulangan kebakaran dan gelar pasukan menghadapi berbagai event/kegiatan penting.

Penerapan identifikasi Bahaya, Penilaian dan Pengendalian Risiko (BPPR) yang meliputi Job Safety Analysis (JSA), Lock Out Tag Out (LOTO) dan izin kerja juga dilakukan oleh pihak PT. PLN (Persero) Rayon Rote Ndao.Penelitian terdahulu yang dilakukan oleh Salafudin M (2013) di PT. PLN (Persero) Area Pengatur Distribusi Jawa Tengah dan D.I.Yogyakarta juga menjelaskan bahwa variabel penerapan SMK3 dilaksanakan dengan baik melalui dukungan secara finansial, PT PLN (Persero) Area Pengatur Distribusi Jawa Tengah dan D.I.Yogyakarta juga berupaya untuk menyediakan personil yang memiliki kualifikasi dengan mengikuti pelatihan $\mathrm{K} 3$, serta menyediakan sarana dan prasarana berkaitan dengan perlengkapan keselamatan kerja yang memadai sesuai Sistem Manajemen K3 yang diterapkan dengan membuat prosedur yang dapat memantau manfaat yang akan didapat maupun biaya yang harus dikeluarkan.

\section{Pengukuran dan Evaluasi}

Upaya implementasi SMK3 yang dilakukan oleh setiap perusahaan termasuk PT.PLN (Persero) Rayon Rote Ndao wajib memperhatikan unsur pengukuran dan evaluasi. Hal ini sangat penting dilakukan agar penerapan SMK3 dapat terukur secara sistematis, sehingga setiap perencanaan program dan kegiatan utama maupun kegiatan pendukung K3 dapat memberi dampak yang signifikan bagi upaya terciptanya lingkungan kerja dan perilaku kerja yang sehat dan dapat menunjang kinerja serta produktivitas karyawan yang tentu saja dapat meningkatkan citra perusahaan secara positif.

Berdasarkan hasil penelitian khususnya pada variabel Pengukuran dan Evaluasi, diketahui bahwa pihak PT.PLN (Persero) Rayon Rote Ndao juga telah melaksanakan pengukuran dan evaluasi dengan baik. Hal ini terlihat dari adanya inspeksi yang dilakukan oleh Unit Pelaksana Pelayanan Pelanggan (UP3) terhadap kinerja manajemen rayon Rote Ndao. Selain itu ada pula audit internal K3 yang dilaksanakan oleh UP3 dan Supervisor K3 meliputi audit K3 mitra kerja yang terdiri dari: Rencana Kerja dan Syarat-syarat (RKS) dan Surat Perintah Kerja (SPK), Sertifikat kompetensi, Standar operational Procedure (SOP), peralatan kerja, Alat Pelindung Diri (APD) dan implementasi sistem manajemen K3 dengan target yakni: Mitra Kerja Listrik Desa, Mitra Kerja MCB-On (CV), Mitra Kerja Perluasan Jaringan, ROW (Right Of Way) atau Tim Perabasan, Pemeliharaan Gardu/Gardu Ukur, Pemeliharaan Meter, Pemeliharaan Jaringan dan Komisioning/Uji Coba Peralatan sebagaimana yang tercantum dalam RKAP tahun 2019.

\section{Tinjauan Ulang dan Peningkatan SMK3}

Unsur terakhir dari SMK3 yang tak kalah pentingnya yakni perlu adanya tinjauan ulang terhadap setiap proses implementasi SMK3 yang dilakukan oleh pihak perusahaan. Berdasarkan hasil penelitian yang dilakukan diketahui bahwa pihak PT.PLN (Persero) Rayon Rote Ndao telah melaksanakan tinjauan ulang terhadap implementasi SMK3 di dalam perusahaannya melalui sosialisasi secara berkelanjutan tentang pentingnya K3 baik itu kepada karyawan, satuan pengamanan dan edukasi kepada mitra kerja pelayanan teknik seperti vendor atau perusahaan mitra maupun juga melalui sosialisasi K3 lintas sektor serta melaporkan unsafe act dan unsafe condition pada pekerjaan yang memiliki risiko tinggi dan menengah seperti pada pekerjaan 
perluasan jaringan listrik, pemasangan trafo, perabasan atau pembersihan jalur jaringan kabel listrik.Sosialisasi secara berkelanjutan tersebut dilaksanakan setiap triwulan dan dikoordinir oleh Supervisor K3.

Evaluasi terhadap para karyawan terkait kepatuhan dalam penggunaan APD dan prinsip-prinsip K3 juga dilakukan secara konsisten oleh Supervisor K3. Salah satu bentuk evaluasi kepatuhan penggunaan APD terhadap para karyawan dilakukan melalui adanya kewajiban mendokumentasikan dan melaporkan setiap pekerjaan yang dilakukan oleh para karyawan kepada pihak manajemen perusahaan dalam hal ini Supervisor K3.

Berdasarkan laporan dokumentasi pekerjaan yang disampaikan oleh para pekerja jaringan kepada pihak manajemen PLN maka supervisor K3 melakukan evaluasi terkait kepatuhan penggunaan APD dan sebagai tindak lanjutnya jika masih didapati ada karyawan yang tidak menggunakan APD saat bekerja maka akan diberikan surat peringatan pertama dan kedua, lalu jika setelah dua kali diberi peringatan tapi masih terjadi pelanggaran aturan juga maka dapat ditindak melalui pemutusan kontrak kerja.

\section{Kendala Penelitin}

Kendala yang dialami peneliti selama penelitian tidak ditemukan kendala dan semua berjalan sesuai dengan proses ydan tujan penelitian.

\section{KESIMPULAN DAN SARAN Kesimpulan}

Berdasarkan hasil penelitian yang dilaksanakan, maka dapat disimpulkan beberapa hal sebagai berikut: 1) Komitmen dan Kebijakan Sistem Manajemen Keselamatan dan Kesehatan Kerja di PT. PLN (Persero)Rayon Rote Ndao telah diterapkan secara baik karena adanya RKAP yang sudah ditetapkan oleh perusahaan; 2) Perencanaan Sistem Manajemen Keselamatan dan Kesehatan Kerjadi PT. PLN (Persero) Rayon Rote Ndao telah diterapkan secara baik karena adanya perencanaan pengadaan dan pembangunan sarana K3; 3) Penerapan Sistem Manajemen Keselamatan dan Kesehatan Kerjadi PT. PLN (Persero)Rayon Rote Ndao telah diterapkan secara baik karena pelaksanaan pekerjaan selalu mengacu pada SOP yang ditetapkan oleh perusahaan; 4) Pengukuran dan Evaluasi Sistem Manajemen Keselamatan dan Kesehatan Kerja di PT. PLN (Persero)Rayon Rote Ndaotelah diterapkan secara baik karena selalu dilakukan pemantauan dan audit internal oleh supervisor K3; 5) Tinjauan Ulang dan Peningkatan Sistem Manajemen Keselamatan dan Kesehatan Kerjadi PT. PLN (Persero)Rayon Rote Ndao telah diterapkan secara baik karena selalu ada inspeksi mendadak (sidak) yang dilakukan oleh supervisor K3 untuk memastikan konsistensi pelaksanaan K3, dan jika ada pelanggaran prosedur maka akan diberi sanksi sesuai dengan aturan internal perusahaan.

\section{Saran}

Berdasarkan hasil penelitian maka, hal-hal yang disaran penulis sebagai berikut:

Bagi PT. PLN Persero Rayon Rote Ndao, perlu adanya pengawasan secara berkelanjutanterhadap konsistensi penggunaan Alat Pelindung Diri (APD) agar efektifitas penerapan K3dapat mengurangi risiko terjadinya kecelakaan maupun penyakit akibat kerja serta meningkatkan mutu dan produktivitas kerja karyawan dan Perlunya peningkatan terhadap pelaksanaan inspeksi dan evaluasi penerapan Sistem Manajemen K3 (SMK3) secara berkelanjutan, seperti pengecekan ketersediaan dan 
kelayakan Alat Pelindung Diri (APD), pengecekan kelengkapan kotak Pertolongan Pertama Pada Kecelakaan (P3K), pengecekan ketersediaan dan kelayakan Alat Pemadam Api Ringan (APAR), pemasangan rambu-rambu K3 pada tempat-tempat strategis dan mudah terlihat oleh karyawan maupun tamu serta perlunya penambahan staf bagi supervisor K3 untuk membantu dan mendukung supervisor K3 sehingga sedapat mungkin dapat terbentuk Panitia Pembina Keselamatan dan Kesehatan Kerja (P2K3) dalam melaksanakan tugas dan tanggung jawab penerapan Sistem Manajemen Keselamatan dan Kesehatan Kerja (SMK3) secara lebih baik.

Bagi instansi pendidikan, perlu adanya penelitian lanjutan, khususnya dibidang Sistem Manajemen Keselamatan dan Kesehatan Kerja. Sementara bagi instansi terkait, perlu melaksanakan pengawasan secara berkelanjutan terhadap penerapan SMK3 perusahan khususnya PT, PLN Persero Rayon Rote Ndao.

\section{DAFTAR PUSTAKA}

Arikunto, S. 2006. Prosedur Penelitian: Suatu Pendekatan Praktik (EdisiRevisi VI). Jakarta: Rineka Cipta.

Notoatmodjo. 2010. Metodologi Penelitian Kesehatan. Jakarta: Rineka Cipta.

Notoatmodjo. 2018. Metodologi Penelitian Kesehatan. Jakarta: Rineka Cipta.

Nugroho, H dan Sallata, M. 2015. Pembangkit Listrik Tenaga Mikro Hidro, Panduan Lengkap Membuat Sumber Energi Terbarukan Secara Swadaya. Yogyakarta: Andi.

Peraturan Pemerintah Republik Indonesia Nomor 50 Tahun 2012.

Riyanto, A. 2011. Aplikasi Metode Penelitian Kesehatan. Yogyakarta: Nuba Medika.

Ramli, S. 2013. Smart Safety Panduan Penerapan SMK3 yang Efektif. Jakarta: Dian Rakyat.

Sakunab, Alexander. 2017. Studi Tingkat Kebisingan dan Dampaknya Terhadap Pekerja Pada Pembangkit Listrik Tenaga Diesel (PLTD) Kefamenanu. Skripsi. Kupang: Fakultas Kesehatan Masyarakat Universitas Nusa Cendana.

Salafudin, M. 2013. Implementasi Sistem Manajemen Keselamatan dan Kesehatan Kerja Di PT.PLN (Persero) Area Pengatur Distribusi Jawa Tengah dan D.I. Yogyakarta Dalam Upaya Peningkatan Mutu dan Produktivitas Kerja Karyawan. Skripsi. Semarang: Fakultas Teknik Universitas Negeri Semarang.

Setiawan, N. I. 2013. Pengaruh Keselamatan Dan Kesehatan Kerja Terhadap Produktivitas Karyawan Pada Departemen Jaringan PT.PLN (Persero) Area Surabaya Utara. Jurnal, diakses pada 05 Desember 2018 di https://jurnalmahasiswa.unesa.ac.id.

Sugiyono. 2010. Metode Penelitian Pendidikan: Pendekatan Kuantitatif, Kualitatif, dan $R \& D$. Bandung: Alfabeta.

Sugiyono. 2014. Memahami Penelitian Kualitatif. Bandung: Alfabeta.

Suma'mur, P. K. 2006. Keselamatan Kerja dan Pencegahan Kecelakaan. Jakarta: CV.Haji Mas Agung.

Tarwaka. 2012. Dasar-Dasar Keselamatan Kerja Serta Pencegahan Kecelakaan Kerja

Di Tempat Kerja. Surakarta: Harapan Press.

Undang-Undang Republik Indonesia Nomor 36 Tahun 2009 Tentang Kesehatan.

Undang-Undang Republik Indonesia Nomor 1 Tahun 1970 Tentang Ketenagakerjaan. Undang-Undang Republik Indonesia Nomor 13 Tahun 2003 Tentang Ketenagakerjaan. Undang-Undang Republik Indonesia Nomor 30 Tahun 2009 Tentang Ketenagalistrikan. 